\title{
António Nóvoa: uma vida para a educação
}

Carlota Boto ${ }^{1}$

\author{
A partilha do trabalho intelectual e das atividades de pesquisa faz-se de modo a \\ possibilitar que cada um busque em si as melhores respostas e contribuições. Lições de inventividade, \\ de pensamento sistemático, precisão conceitual e de linguagem aparecem assim disponiveis em \\ situações de diálogo. \\ Denice Barbara Catani
}

\section{Resumo}

Um dos maiores especialistas internacionais no campo da História da Educação, António Nóvoa também se notabilizou no campo da Educação Comparada e no território do que poderíamos compreender por história da formação docente. É autor de referência nos estudos a respeito das políticas educativas, especialmente aquelas desenvolvidas pela União Europeia. É reputado como um dos maiores conhecedores do repertório da área da educação, tendo absoluto reconhecimento internacional, especialmente na Europa e nas Américas do Norte e do Sul. Hoje é, nesse sentido, uma voz fundamental no debate educacional contemporâneo, abordando aspectos acerca da organização histórica e da atualidade do moderno modelo escolar. Sua obra confere maior historicidade à educação comparada e introduz a comparação nos estudos históricos. Ele preocupa-se em desenvolver trabalhos de pesquisa voltados para a conexão entre a dimensão local e a estatura global. A inventividade de seu trabalho tem sido reconhecida pelo impacto de sua obra em termos internacionais. Nesta instigante entrevista, António Nóvoa conta-nos como se formou professor, faz uma avaliação de seu percurso no campo da História da Educação e oferecenos pistas para analisar a escola contemporânea e o traçado por ela desenhado com vistas ao futuro.

\section{Palavras-chave}

António Nóvoa - História da educação - Formação de professores - Educação comparada - Modelo escolar.

1- Faculdade de Educação, Universidade de São Paulo, São Paulo, SP, Brasil. Contato: reisboto@usp.br 


\section{António Nóvoa: a life for education}

\section{Abstract}

One of the greatest international experts in the field of History of Education, Antonio Nóvoa was also notable in the field of Comparative Education and in the territory of what we could understand by history of teacher education. He is a reference author in studies on educational policies, especially those developed by the European Union. He is regarded as one of the greatest experts in the field of education, with absolute international recognition, especially in Europe and North and South America. Today he is, in this sense, a key voice in the contemporary educational debate, addressing aspects about the historical organization and the current "school model". His work gives greater historicity to comparative education and introduces comparison in historical studies. He is concerned with developing research papers focused on the connection between the local dimension and global stature. The inventiveness of his work has been recognized by the impact of his writings internationally. In this instigating interview, António Nóvoa tells us about his teacher training, makes an evaluation of his career in the field of history of education, and offers us clues to analyze the contemporary school and its design with a view to the future.

\section{Keywords}

António Nóvoa - History of education - Teacher training - Comparative education School model.

\section{Apresentação}

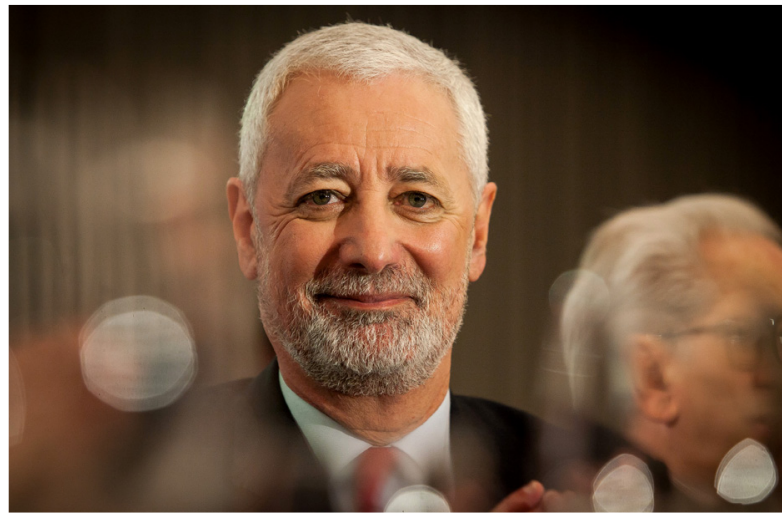

Fonte: Arquivo pessoal do entrevistado.
António Manuel Sampaio da Nóvoa, nascido em Valença do Minho em Portugal, no dia 12 de dezembro de 1954, é professor catedrático do Instituto de Educação da Universidade de Lisboa, instituição na qual leciona desde 1986. É reitor honorário da Universidade de Lisboa, onde ocupou a reitoria entre 2006 e 2013. Nessa oportunidade, António Nóvoa liderou o processo de fusão da referida Universidade com a Universidade Técnica de Lisboa, duas importantes universidades públicas que, unidas, contribuíram para fortalecer o cenário acadêmico português. Antes disso, a partir de 2002, atuou como vice-reitor, a convite do Prof. Dr. José Barata-Moura (HOFSTETTER, 2016). 
Em sua adolescência, tendo sido convidado para integrar a equipe de futebol da Acadêmica em Coimbra, aos 16 anos matriculou-se no curso de Matemática da Universidade de Coimbra. Nessa época, foi delegado da Associação dos Estudantes e dividia seu tempo entre os estudos, o futebol e o Teatro dos Estudantes da Universidade de Coimbra. Depois regressou a Lisboa para frequentar a Escola de Teatro do Conservatório Nacional, com uma Bolsa da Fundação Calouste Gulbenkian. Depois de fazer estudos de Teatro, migrou para os estudos de pedagogia e concluiu sua formação em Ciências da Educação pela Universidade de Genebra (1982).

António Nóvoa fez o doutoramento também na Universidade de Genebra, no ano de 1986, com uma tese acerca do processo de profissionalização de professores em Portugal. Essa tese foi considerada por Daniel Hameline, na ocasião, como uma virada na historiografia da educação portuguesa e, mesmo em nível internacional, nos estudos da História da Educação. Em 2006, concluiu também um doutorado em História, pela Universidade de Paris IV - Sorbonne, a respeito do modelo escolar no sudoeste europeu, particularmente na França, na Espanha e em Portugal (BARATA-MOURA, 2015). É doutor honoris causa pela Universidade do Algarve (2015), pela Universidade de Brasília (2015) e pela Universidade Federal do Rio de Janeiro (2017).

António Nóvoa participou ativamente da criação da Sociedade Portuguesa de Ciências da Educação, entre 1989 e 1990. Foi Presidente do Conselho Científico da Faculdade de Psicologia e Ciências da Educação da Universidade de Lisboa, nos anos 1999 a 2001. Entre 2000 e 2003, foi presidente do ISCHE (International Standing Conference for the History of Education), principal associação internacional de História da Educação. Atuou também junto à revista Paedagogica Historica, que é provavelmente a revista científica mais importante nos domínios da História da educação.

Sua atuação como homem público sempre foi também muito destacada. Em 2014, ele recebeu o prêmio Universidade de Coimbra por sua "notável carreira e trabalho no campo da educação”. Desempenhou funções públicas de relevo, como - entre 1996 e 1999 - a de consultor de educação do Presidente da República Portuguesa Jorge Sampaio. Recebeu a Grã-Cruz da Ordem da Instrução Pública em 2005, a Ordem do Rio Branco do Presidente da República Federativa do Brasil, em 1998, entre outras inúmeras homenagens e condecorações. Candidato a Presidente da República nos anos 2015 e 2016, recebeu 23\% dos votos, a maior votação já alcançada por um candidato independente. Hoje é embaixador de Portugal na UNESCO, nomeado pelo Primeiro Ministro e pelo Presidente da República Portuguesa.

Um dos maiores especialistas internacionais no campo da História da educação, António Nóvoa também se notabilizou no campo da Educação Comparada e no território do que poderíamos compreender por história da formação docente. É autor de referência nos estudos a respeito de políticas educativas, especialmente aquelas desenvolvidas pela União Europeia. É reputado como um dos maiores conhecedores do repertório da área da educação, tendo absoluto reconhecimento internacional, especialmente na Europa e nas Américas do Norte e do Sul.

Hoje é, nesse sentido, uma voz fundamental no debate educacional contemporâneo, abordando aspectos acerca da organização histórica e da atualidade do moderno modelo 
escolar. Sua obra confere maior historicidade à educação comparada e introduz a comparação nos estudos históricos. Ele preocupa-se em desenvolver trabalhos de pesquisa voltados para a conexão entre a dimensão local e a estatura global. A inventividade de seu trabalho tem sido reconhecida pelo impacto de sua obra em termos internacionais e também pelo vigor das teses que dirigiu como orientador. Orientou por volta de 30 doutoramentos e 50 mestrados. Sua bibliografia consiste aproximadamente de 200 títulos, principalmente artigos em periódicos acadêmicos e livros publicados em Portugal, na Alemanha, na Bélgica, no Brasil, no Canadá, na Colômbia, na Espanha, nos Estados Unidos da América, na Finlândia, na França, na Grécia, na Inglaterra, nos Países Baixos, na Suécia e na Suíça.

Tendo formado investigadores dentro e fora do país, o professor António Nóvoa singulariza-se por sua sensibilidade intelectual e tato pedagógico. Capaz de aliar rigor teórico e vigor na escrita, tem um estilo de redação muito próprio, responsável, em parte, pelo enorme sucesso de sua produção intelectual. Com leitores no mundo inteiro, são apropriadas as palavras de José Eduardo Franco, em Trinta figuras empreendedoras da cultura portuguesa:

[...] determinação, inteligência teórico prática afinada, perspicácia, ousadia crítica, capacidade de liderança e comunicação persuasiva, este historiador e pedagogo, e reitor da Universidade de Lisboa, é uma voz que se faz ouvir em prol de uma séria viragem nos rumos do país (FRANCO, 2013, p. 293).

Na mesma oportunidade, José Eduardo Franco adenda que António Nóvoa agrega talentos inatos com uma esmerada educação de base:

[...] com participação competente em diferentes experiências de intervenção e organização social, cultural, desportiva, artística e acadêmica, com realismo e discernimento, com o gosto de fazer coisas bem feitas, com lógica e com cunho de originalidade (FRANC0, 2013, p. 293).

António Nóvoa teve importante papel na internacionalização da universidade portuguesa, especialmente como idealizador e coordenador de inúmeros projetos acadêmicos coletivos, nos quais agregava pesquisadores estrangeiros. Formou inúmeras redes de trabalho e gestou iniciativas da mais elevada qualidade, incluindo o Projeto Prestige, liderado no Brasil pela professora Denice Catani. Sendo a pesquisadora que, em nosso país, mais desenvolveu trabalhos em parceria com António Nóvoa, Denice Catani $(2011$; 2015) assinala o seguinte:

A obra de António Nóvoa possui o atributo de fazer proliferar nossas ideias e questões - e é bem provável que esta seja uma das razões principais que ajudem a compreender a intensidade de sua presença nas reflexões educacionais contemporâneas, especialmente, mas não apenas, em Portugal e no Brasil. Seus escritos incidem sobre vários problemas da pedagogia e investigam territórios diversos no campo educacional: a história da educação e a formação dos professores têm sido objetos de seus trabalhos mais conhecidos em nosso país. As políticas educativas e a 
educação comparada, no entanto, também comparecem como objetos de suas reflexões e análises. Sua presença no campo educacional brasileiro, desde o início dos anos 90, foi decisiva para o fortalecimento do intercâmbio de ideias e para a cooperação acadêmica entre pesquisadores de Portugal e do Brasil. (CATANI, 2011, p. 30).

António Nóvoa passou longos períodos no exterior, desenvolvendo atividades de docência e, principalmente, de investigação: entre 1982-83, trabalhou na Universidade de Genebra na Suiça; entre 1993-94, esteve na Universidade de Wisconsin-Madison, nos Estados Unidos da América; em 1995 pesquisou na Universidade de Paris V/INRP, na França; em 2001, Universidade de Oxford, na Inglaterra; em 2002, lecionou no Teachers College da Universidade de Columbia-Nova York, nos Estados Unidos da América; e, finalmente, entre 2013 e 2014, esteve na Universidade de Brasília e em 2017, na Universidade Federal do Rio de Janeiro, no Brasil.

António Nóvoa é um dos educadores mais citados na produção bibliográfica brasileira, sendo - de maneira mais ampla - um dos teóricos que mais bem circulam no debate pedagógico da atualidade. Em 2002, a revista Nova Escola colocou-o entre as seis personalidades pedagógicas mais importantes para serem conhecidas no Brasil. Por sua vez, a também brasileira revista Educação publicou uma biografia, identificando António Nóvoa como um dos principais dez nomes internacionais para se entender a educação contemporânea. Em 2011, António Nóvoa foi considerado uma das vinte principais referências educacionais no espaço mediterrânico.

Quando do recebimento de seu doutorado honoris causa pela Universidade do Algarve, António Nóvoa falou em liberdade, conhecimento e compromisso, como as três máximas que marcaram sua atuação intelectual e institucional, quer como docente/ investigador quer como homem público e reitor. Recordou, na ocasião, que sua formação inicial vinha das artes, especificamente do teatro, para depois chegar à educação e à história. Com as artes, Nóvoa aprendeu a dimensão da criação, necessária à produção do conhecimento, para que a atividade da pesquisa e do ensino possa ser mais do que a repetição de fórmulas consagradas.

António Nóvoa, membro do Conselho Editorial da revista Educação e Pesquisa, foi inúmeras vezes conferencista convidado da Faculdade de Educação da USP, destacando-se sua mais recente conferência, intitulada Pedagogia: a terceira margem do rio, que aconteceu no Auditório da Escola de Aplicação da USP, a convite do Instituto de Estudos Avançados e de nossa Faculdade.

Ao longo de sua obra, António Nóvoa postula a existência de um moderno modelo escolar, que acompanhou os anos que se seguiram ao século XVI. Nesse primeiro momento, do XVI ao XVIII, esse modelo escolar corresponderia a uma forma, que a escola foi paulatinamente adquirindo. Depois, a partir do final do século XVIII e, sobretudo, no decorrer do XIX, mas chegando também ao XX e ao XXI, esse modelo, essa forma de escola será assumida pelo Estado, que passa a ser a instância reguladora das práticas educativas escolares.

Assim, de um ciclo da Igreja, passou-se ao ciclo do Estado. Todavia, foi apenas no final do século XIX que se disseminou a "gramática da escola moderna” (TYACK; CUBAN, 
1995). A partir de então, estaria consolidado o que alguns autores nomearam de "forma escolar de socialização" (VINCENT, 1980; 1994), outros chamaram de "cultura escolar" (JULIA, 2001; VIDAL, 2005); e que Nóvoa prefere chamar de moderno "modelo escolar" (NÓVOA, 1987).

Crítico dos críticos da escola, Nóvoa considera que a escolarização tem uma função complexa: tem tanto um papel de atestação de uma ordem quanto de contestação da mesma ordem. Isso significa que a escola reproduz sim os valores, as posições e as formas de agir de outras instâncias da sociedade. Não obstante, a escola também cria um caldo cultural que ela espraia para fora de si mesma; e que acaba impregnando as demais esferas da vida social. Nesse sentido, pode-se dizer que a escolarização cria cultura, transmite cultura e pode mesmo chegar a transformar a vida cultural de uma dada sociedade. A escola tem uma tarefa importante na formação e adesão da população a valores e a todo um código normativo. Além disso, a profissão de professor constrói e reelabora permanentemente um conjunto de saberes e um saber fazer.

Para Nóvoa, houve similaridade, se considerarmos uma história comparada da educação, no que diz respeito ao processo de profissionalização da profissão docente. 0 percurso de constituição do professorado tendencialmente obedeceu aos seguintes momentos. Uma primeira etapa, de estruturação da atividade docente como exercício a tempo inteiro - como ocupação profissional exclusiva dos professores. Uma segunda fase em que se estabeleceu um suporte legal para o exercício da atividade docente; e que no mundo luso-brasileiro se traduziu pela licença-docente concedida pelo Estado pombalino. Um terceiro momento foi a criação de instituições específicas para a formação de professores; e uma quarta etapa correspondeu à configuração de associações profissionais de professores (NÓVOA, 1991, p. 17).

Nóvoa compreende que, na lógica da profissionalidade docente, os saberes devem ter um elo com as disciplinas científicas e outro elo com as práticas e com uma dimensão instrumental. Nesse sentido, há um dado processo de reconfiguração pedagógica dos conhecimentos provenientes dos vários campos do saber humano. Além disso - o que é fundamental - os docentes aderem a um conjunto de normas deontológicas e constroem, a partir delas, sua identidade como professores.

Nóvoa, em alguns dos seus escritos, refere-se à colegialidade docente como um desafio que a história do tempo presente apresenta para os professores. Deslocando-se, com facilidade, da história da educação para a escola dos dias de hoje, Nóvoa transita pelos principais impasses que interpelam a escolarização. Suas palavras são acompanhadas por auditórios lotados, que se identificam com sua precisão conceitual e com sua capacidade analítica para pensar, para projetar e para interagir com os problemas do campo da educação. Trata-se de uma das principais vozes do debate pedagógico contemporâneo. E hoje, ele fala conosco (VIDAL; RABELO, 2018; LIMA; GIL, 2016; SANTOS, 2013). 


\section{Referências}

BARATA-MOURA, José. Alocução na cerimónia do doutoramento honoris causa de António Sampaio da Nóvoa pela Universidade do Algarve. Lisboa: Universidade de Lisboa, maio de 2015. Disponível em: <http://docplayer. com.br/58475599-Alocucao-na-cerimonia-do-doutoramento-honoris-causa-de-antonio-sampaio-da-novoa-pelauniversidade-do-algarve.html>. Acesso em: 11 jun. 2018.

CATANI, Denice Barbara. António Nóvoa: um pensamento fecundo da história da educação. In: REG0, Teresa Cristina. Memória, história e escolarização. Petrópolis: Vozes, 2011. p. 29-54.

CATANI, Denice Barbara; GATTI JÚNIOR, Décio (Org.). 0 que a escola faz? Elementos para a compreensão da vida escolar. Uberlândia: Edufu, 2015.

FRANCO, José Eduardo. António Nóvoa - construir futuros possíveis. In: FRANCO, José Eduardo. Portugal empreendedor: trinta figuras empreendedoras da cultura portuguesa. Lisboa: Imprensa Nacional Casa da Moeda, 2013. p. 293-307.

HOFSTETTER, Rita. Eloge de António Manuel Seixas Sampaio da Nóvoa. Lisboa: [s. n.], 25 out. 2016. (Mimeografado).

JULIA, Dominique. A cultura escolar como objeto histórico. Revista Brasileira de História da Educação, Campinas, v. 1, n. 1, p. 9-43, 2001.

LIMA, Ana Laura Godinho; GIL, Natália de Lacerda. Sistemas de pensamento na educação e políticas de inclusão (e exclusão) escolar: entrevista com Thomas S. Popkewitz. Educação e Pesquisa, São Paulo, v. 42, n. 4, p. 1-29, out./ dez. 2016.

NÓVOA, António. Le temps des professeurs: analyse socio-historique de la profession enseignante au Portugal (XVIII' ${ }^{2}$-XXa siècle). v. 1-2. Lisboa: Instituto Nacional de Investigação Científica, 1987.

NÓVOA, António (Org.). Profissão professor. Porto: Porto Editora, 1991.

SANTOS, Lucíola Licínio. Entrevista com António Nóvoa. Educação em Perspectiva, Viçosa, v. 4, n. 1, p. 224-237, jan./jun. 2013.

TYACK, David; CUBAN, Larry. Tinkering toward utopia: a century in public school reform. London: Harvard University Press, 1995.

VIDAL, Diana Gonçalves. Culturas escolares: estudo sobre práticas de leitura e escrita na escola pública primária (Brasil e França, final do século XIX). Campinas: Autores Associados, 2005.

VIDAL, Diana; RABELO, Rafaela. Gênero e história da educação: itinerários de Rebecca Rogers. Educação e Pesquisa, São Paulo, v. 44, p. 1-11, maio 2018.

VINCENT, Guy. L'école primaire française: étude sociologique. Lyon: Presses Universitaires de Lyon: La Maison des Sciences de l'Homme, 1980.

VINCENT, Guy. L'éducation prisionniére de la forme scolaire: scolarisatino et socailisation dans les societés industrielles. Lyon: Presses Universitaires de Lyon, 1994. 


\section{Entrevista}

Como você caracterizaria seu processo de socialização primária? Quais foram os pilares de sua educação familiar?

Nasci no Alto Minho, em Valença, na fronteira com a Galiza. É a minha mátria, a terra da minha mãe. Sempre tive um grande fascínio pelo rio Minho, mesmo ao lado. Fronteiras e rios: duas metáforas que têm acompanhado a minha vida.

A referência principal da minha infância é a Quinta de Boamense, no Baixo Minho, perto da cidade do Porto. É a minha pátria, a terra do meu pai. Aqui viveu, no século XIX, o historiador Alberto Sampaio. Aqui passou boas temporadas o seu amigo Antero de Quental. Dois membros da mais importante geração intelectual do Portugal contemporâneo: a geração de 1870 .

Família grande, tradicional, religiosa. Eu e os meus quatro irmãos tivemos uma educação austera, mas sempre marcada por um espírito de liberdade e independência. Bases sólidas, sim, mas uma grande abertura para cada um escolher o seu caminho.

0 meu pai é juiz. A ideia de justiça, de julgar com independência, de tratar igualmente uns e outros, os que pensam como nós, e os que não pensam, os que gostam de nós, e os que não gostam, é o pilar central da minha educação familiar.

Você se recorda de algum episódio de sua vida escolar que tenha sido marcante e determinante da futura perspectiva que você desenvolveria sobre o modelo escolar?

A minha vida escolar foi bastante normal. Fui um aluno razoável, com um percurso escolar tranquilo, apenas perturbado por um ou outro episódio relacionado com atitudes injustas dos professores, em relação a mim ou aos meus colegas. Não há nada que afete mais a autoridade de um professor, a sua relação com os alunos, do que a injustiça.

A escola deu-me uma disciplina de estudo e de trabalho. Neste sentido, a disciplina é o que nos permite a liberdade. Se não aprendermos a disciplina da leitura, os seus códigos e as suas práticas, ficaremos excluídos dos mundos infinitos que só os livros nos podem abrir. 0 mesmo se diga da matemática ou da ciência ou das artes.

A escola deu-me também a possibilidade de conviver, de viver com os outros. Eu e os meus irmãos frequentamos sempre escolas públicas. Foi aqui que encontramos crianças e jovens diferentes de nós e com eles construímos relações que, em alguns casos, têm durado a vida inteira. Também na escola, e isso foi muito importante, iniciei atividades desportivas e artísticas que foram essenciais na minha formação.

Reconheço a importância da escola nessas duas dimensões: aprender a estudar e aprender a conviver. Essas bases foram decisivas. Sem elas, nada teria sido possível. Porém, as minhas aprendizagens mais significativas foram feitas fora da escola. Os livros que li, as pesquisas que realizei, os trabalhos em que me envolvi, os projetos que levei a cabo, mais tarde, as aulas que preparei e os textos que escrevi, foi isso que, verdadeiramente, me instruiu e educou. Não quero romancear os processos de autoeducação, ou de autoformação, à maneira de um Oscar Wilde, de um Bernard Shaw ou mesmo de um Adolphe Ferrière. Mas o essencial da minha educação fez-se em ambientes exteriores à escola. 
Gostaria de ver esses outros ambientes dentro da escola? Certamente. Ambientes de estudo individual e em grupo. Ambientes de pesquisa e de cooperação. Ambientes de trabalho em torno de projetos. Ambientes de participação em atividades científicas e artísticas. Gostaria que estes ambientes substituíssem o tradicional modelo escolar? Certamente.

Podemos explicar o modelo escolar a partir das três unidades do teatro clássico: o espaço, o tempo e a ação. A escola tem lugar em um espaço pré-definido, um edifício específico para essa função, com salas de aulas idênticas em todo o mundo. A escola tem uma estrutura horária bem definida, com tempos fixos, pautados pela sequência das aulas e das disciplinas. A escola baseia-se em uma ação intencional, propositiva, de um professor, que leciona as suas aulas a uma turma de alunos.

Essa descrição é uma caricatura. Mas permite identificar três movimentos que marcam a metamorfose da escola, isto é, a mudança da forma da escola. Primeiro - a passagem de um espaço fixo, pré-defınido, para uma diversidade de espaços, aproveitando mesmo, do ponto de vista educativo, ambientes e realidades exteriores à escola. Segundo - a reorganização do tempo diário e semanal, que será marcado mais pela cadência do estudo, da realização de pesquisas e de projetos de trabalho do que pela habitual estrutura do horário escolar. Terceiro - a construção de lógicas de trabalho e de aprendizagem, em cooperação, através do envolvimento de vários professores em conjunto com várias turmas de alunos, construindo modalidades diferentes de ação pedagógica.

Em todo o mundo, a escola está a viver um processo de metamorfose. 0 modelo escolar que se difundiu a partir de meados do século XIX está, agora, a transformar-se, a mudar de forma. É este o futuro da escola, um futuro que já vai estando presente em muitas escolas por esse mundo fora.

Você revelou um percurso original em sua formação; e, sobretudo, uma formação interdisciplinar, que passou pelo esporte, pelas artes, notadamente o teatro, tendo depois se especializado no campo da educação e da história. 0 que você levou do esporte e do teatro para sua vida como professor?

Historicamente, as universidades cultivaram os princípios da educação liberal, no sentido anglo-saxônico do termo, uma educação generalista, de base humanista e científıca. Esses princípios têm sido postos em causa pela excessiva especialização dos cursos e, mais recentemente, pelas teses da empregabilidade. Na Europa, ao reduzir os bacharelados para três anos, o Processo de Bolonha contribuiu para o estreitamento dos estudos universitários.

Não podemos aceitar que um engenheiro desconheça as artes e as humanidades, assim como não podemos aceitar que um filósofo ignore as ciências. Já ouvi físicos afirmarem que nunca tinham ido a um concerto e também artistas dizerem que nada sabiam de matemática. São duas formas distintas, igualmente graves, de analfabetismo e de incultura.

Abel Salazar, uma personalidade de referência na sociedade portuguesa, ficou conhecido por uma frase emblemática: "Um médico que só sabe medicina, nem medicina sabe”. No meu tempo de Reitor da Universidade de Lisboa, lançamos um bacharelado em Estudos Gerais. Com o apoio de um professor, os alunos podem compor o seu programa 
de estudos com base em disciplinas de diversas Escolas (Artes, Humanidades, Ciências). Foi um gesto importante para marcar o sentido de uma verdadeira educação superior.

A minha formação é feita de uma circulação por campos muito distintos. Por vezes, sinto-me um generalista, que não consegue ir além de um olhar superficial sobre várias áreas de conhecimento. Outras vezes, acredito que a capacidade de juntar diferentes universos nos alarga o olhar e a capacidade de visão. É um dilema que marca a minha vida.

A pergunta faz-me recordar um apontamento de Albert Camus, que um dia disse: "o pouco que sei de moral, aprendi-o nos campos de futebol e nos palcos de teatro que têm sido as minhas verdadeiras universidades". Também para mim, o esporte e as artes tiveram, e têm, um grande significado. E ajudaram-me muito a construir a minha identidade docente. 0 esporte é o espaço dos talentos individuais ao serviço de dinâmicas coletivas, é o lugar do treino e da preparação, mas também do improviso, é o reforço da cooperação e o esforço conjunto. Não há nada melhor para compreender a natureza humana do que um campo de jogo. Essa vivência é muito importante para construir uma relação de cooperação e de trabalho com os outros. E o que é a pedagogia, se não isso mesmo?

As artes são o espaço da nossa inscrição na humanidade. A curiosidade, a invenção, a criação. A procura do que nos distingue. Não podemos ser apenas copiadores ou imitadores. Porque "poesia é voar fora da asa”, como escreve Manoel de Barros. A realidade da arte é muito importante para compreender a importância de irmos além do que já é conhecido. E o que é a educação, se não isso mesmo?

Para que serve um professor? Para organizar o trabalho dos alunos, de forma cooperativa, fazendo sobressair as qualidades de cada um. Para promover a curiosidade e a invenção, sabendo que o gênio exige muito esforço e dedicação. Aí estão o esporte e as artes, que tanto me ensinaram a ser professor.

Em sua tese de doutorado, defendida, sob o título Le temps des professeurs, na Universidade de Genebra, você aponta algumas características na trajetória histórica do processo de profissionalização dos professores. Gostariamos de lhe ouvir um pouco sobre esse percurso.

Os professores tornaram-se o mais numeroso grupo profissional, com formação superior, nas sociedades do século XX. A minha intenção foi estudar a forma como se construiu historicamente esse processo de profissionalização, como se passou de uma atividade circunstancial e fortuita (no caso das primeiras letras, praticamente qualquer pessoa podia exercer a docência em sua casa ou na sua oficina, de forma regular ou esporádica) para uma profissão fortemente organizada com regras de recrutamento, de formação e de trabalho definidas pelo Estado.

Na época em que escrevi a minha tese (anos 1980), os conceitos de profissão e de profissionalização estavam muito marcados pela literatura anglo-saxónica, isto é, pelos ideais das profissões liberais. Não era esta a abordagem que me interessava, mas antes a compreensão de um processo histórico que tem um momento forte no final do século XVIII, com a emergência dos primeiros sistemas estatais de ensino, como é o caso das reformas pombalinas em Portugal e no Brasil, e que se consolida, em definitivo, na segunda metade do século XIX. 
0 momento mais decisivo deste processo é a criação das Escolas Normais para a formação de professores, em meados do século XIX. É certo que o ensino normal foi acabando, em todo o mundo, de forma penosa, a partir da segunda metade do século XX, com a passagem da formação de professores para o ensino superior. Mas, durante cem anos, as Escolas Normais desempenharam um papel importantíssimo, não só na formação dos professores, mas também no desenvolvimento de meios e métodos de ensino, na produção de materiais didáticos e na inovação pedagógica, no lançamento de iniciativas de aperfeiçoamento e de formação continuada, no associativismo docente, nas publicações sobre educação e ensino (livros e jornais) e no apoio às políticas públicas. Em grande parte, é nas Escolas Normais que se constrói o modelo escolar e que se produz a profissão de professor. É por este motivo que grande parte do meu trabalho procura ligar as questões da formação de professores e da profissão docente.

As dificuldades históricas da profissionalização dos professores prendem-se com dois aspectos que, ainda hoje, não estão resolvidos: a constituição de um corpo de conhecimentos específico dos professores; e a sistematização de um conjunto de valores estruturantes da identidade docente.

No primeiro caso, verifica-se que a expansão do campo docente se tem feito a partir da valorização do saber dos especialistas, por um lado, das diferentes disciplinas (matemática, história etc.), por outro lado, das ciências da educação (currículo, avaliação etc.). Esses dois tipos de conhecimento são fundamentais, e não são separáveis do ponto de vista pedagógico, contrariamente ao que certas oposições e dicotomias fazem crer; mas nem um nem outro dispensam um conhecimento profissional docente, construído a partir de dentro da profissão, e que tem sido historicamente muito frágil. No segundo caso, observa-se que os professores continuam muito dependentes de regulações externas, sobretudo do Estado, faltando uma definição autônoma dos princípios e das normas éticas da ação docente. Essa ausência diminui a liberdade dos professores, no plano individual e coletivo, bem como a responsabilização dela decorrente, no plano interno da escola e na projeção externa da profissão. É por isso que as questões deontológicas estão sempre ligadas com os debates acerca da autonomia profissional.

Alguns anos depois da tese, escrevi um artigo a respeito dos professores com três perguntas: Quem são? Donde vêm? Para onde vão? Esse título retrata bem o movimento da minha tese: partir do presente, para o iluminar do ponto de vista histórico e, assim, abrir novas perspectivas para pensar o futuro.

Em sua outra tese de doutorado, defendida na área de História, na Sorbonne, você desenvolve uma história comparada da educação, estudando os casos de Portugal, Espanha e França. 0 que você identifica como elementos comuns na trajetória da escola primária nesses três países?

A minha primeira tese de doutoramento, defendida em Genebra no ano de 1986, baseia-se em uma análise sócio-histórica, cruzando as perspectivas da Nova História com um olhar sociológico. As influências de Max Weber, Philippe Ariès, Norbert Elias ou Michel Foucault são muito nítidas. 
A minha segunda tese de doutoramento, apresentada em Paris, no ano de 2006, procura resgatar uma história comparada da educação, isto é, pensar a comparação a partir de um olhar histórico ou, dito de outro modo, dar uma espessura histórica à comparação.

0 ponto de partida é simples: a famosa linha Saint-Malo/Genebra que separa a França em duas metades. Ao Norte, o país protestante, alfabetizado e desenvolvido. Ao Sul, o país católico, com índices baixos de alfabetização e atrasos significativos no desenvolvimento. Sabemos que a divisão não se faz apenas pelo fator religioso, como bem explicam François Furet e Jacques Ozouf, mas, antes, por um equilíbrio entre a procura social de educação (a partir de baixo, pela sociedade) e a oferta de educação (a partir de cima, pelo Estado).

Mas a ruptura protestante, no século XVI, fez um apelo à leitura da Bíblia, incentivando os processos de alfabetização. Na Europa do Sul, católica, a leitura e a interpretação da Bíblia permanecem responsabilidade do clero, e não dos crentes. No final do século XIX, quando a alfabetização estava generalizada na Europa do Norte, em Portugal os níveis de analfabetismo situavam-se ainda nos 80\%.

Se prolongarmos a linha Saint-Malo/Genebra, encontramos, a Sul, uma parte da França, a Espanha, Portugal, a Itália e a Grécia. Não tive condições para estudar o caso italiano, e a situação grega tem contornos muito distintos. Centrei-me nos três países do Sudoeste Europeu que revelam mais semelhanças do que diferenças. De todas as formas, o meu interesse não era, sobretudo, uma comparação direta entre os três países, mas antes uma comparação entre esses países e os processos mundiais de construção do modelo escolar.

Naturalmente, a tese termina com um epílogo, Para acabar com a escola, no qual se faz a crítica ao modelo escolar e se avançam algumas hipóteses de reflexão a respeito do futuro da educação.

Sua obra no campo da história da educação foi reconhecida como referência internacional. Como você caracterizaria hoje os estudos da história da educação? Você que já estudou para suas provas de agregação as diferentes etapas em que a história da educação se constituiu como disciplina de estudo.

A História da educação constituiu-se como disciplina no final do século XIX, em ligação com a consolidação dos grandes sistemas nacionais de ensino. Naquela época, lançaram-se importantes reformas de educação, que necessitam de ser historicamente legitimadas. Os primeiros grandes textos e manuais de História da Educação surgiram nesse período, precisamente no mesmo momento em que se criaram as primeiras cátedras de Ciência da Educação.

Depois da virada do século, os estudos históricos em educação perderam grande parte do seu interesse. Um novo ímpeto só teve lugar nos anos 1960, na sequência das novas dinâmicas da história social e cultural. As últimas décadas do século XX são um tempo muito rico e estimulante, com a publicação, em todo o mundo, de trabalhos de grande qualidade.

Em um artigo que escrevi para a revista francesa Histoire de l'Éducation, em 1997, apresentei seis linhas de evolução que, em certo sentido, traduzem o vigor da nova História da Educação: 
1) Das estruturas aos atores: para valorizar as pessoas e as histórias contadas a partir das suas biografias, percursos e pontos de vista;

2) Do sistema às escolas: para iluminar, não apenas uma visão de cima, mas também as realidades concretas e o quotidiano das instituições escolares;

3) Da externalidade à internalidade: para equilibrar um olhar de fora com uma análise das dinâmicas internas das escolas;

4) Das ideias aos discursos: para completar uma história das ideias pedagógicas com uma sociohistória do conhecimento e dos seus modos de produção;

5) Dos fatos às políticas: para escapar a uma descrição puramente cronológica dos fatos educativos, nomeadamente das reformas, e compreender os diversos processos de mudança em educação; e

6) Do nacional ao local/global: para ir além de uma história estritamente nacional e reconciliar a história com a comparação, isto é, com diferentes níveis de espaço-tempo.

Devemos desconfiar deste tipo de arrumações, ou tipologias, que são sempre redutoras. Mas, apesar de tudo, permitem compreender movimentos que foram significativos para a História da Educação e para o reforço das suas comunidades de pesquisa. 0 final do século XX, tal como o final do século XIX, foi um tempo-forte dos estudos históricos em educação.

Mas, uma vez mais, parece estar a acontecer um empobrecimento da disciplina. Por quê? Talvez seja possivel avançar duas explicações.

A primeira explica-se pelo fato de o novo milênio ter nascido com uma grande inclinação para visões futuristas da educação, preocupadas com os "cenários de futuro", com as prodigiosas "evoluções tecnológicas" ou com os "novos caminhos da aprendizagem". Gostaria de colocar entre aspas as últimas três expressões para delas me distanciar, não porque esse pensamento seja inútil, mas porque parte, regra geral, de um apagamento da história. Como se as novidades em educação só conseguissem legitimar-se esquecendo do passado e até do presente. E, no entanto, é precisamente o contrário: a inovação é um caminho, um processo, e não uma aparição do nada.

A segunda explicação está no próprio trabalho dos historiadores da educação. A especialização e a fragmentação das suas pesquisas tornam difícil uma visão integrada e abrangente dos fenômenos educativos. Quando se percorrem as listas das comunicações apresentadas aos congressos científicos ou dos artigos publicados nas revistas de referência, deparamo-nos com muitos trabalhos parcelares, cujo somatório não apresenta uma interpretação clarividente. Sucedem-se estudos tecnicamente bem feitos, mas que parecem apenas confirmar o que já sabemos, aos quais faltam um novo olhar e uma visão diferente. A sua originalidade reside na tentativa de preencher pedaços da história ainda desconhecidos (um pedagogo, uma escola, uma reforma, um periódico...), mas não revelam a curiosidade, a dúvida e a ambição que definem o gesto intelectual. Receio bem que, continuando por esse caminho, a História da Educação entre em um período de marasmo e de estagnação.

Há quase vinte anos, a revista Educação e Pesquisa publicou um texto proveniente de uma importante conferência que você proferiu na Faculdade de Educação da USP, na qual você falava do excesso dos discursos e da pobreza das práticas. Você mantém esse diagnóstico? Ou daquele tempo para cá, você diria que as coisas se alteraram? 
É no momento em que preparo uma aula ou uma conferência que as ideias ganham forma e sentido para mim. Quando procuro a melhor maneira de transmitir aos outros aquilo que penso, não estou a fazer apenas um exercício de transmissão aos outros do que já sei. Não. É nesse preciso momento que me surgem ideias nas quais ainda não havia pensado. Regra geral: é só depois de ter comunicado alguma coisa que a consigo escrever. Com exceção dos meus trabalhos mais longos, nomeadamente as teses de doutoramento, a oralidade precede quase sempre a escrita.

Foi o que aconteceu com essa conferência na USP, de que me recordo muito bem. Procurei denunciar um excesso dos discursos que, infelizmente, esconde uma pobreza das práticas. Analisemos apenas duas dimensões: as políticas educativas e a formação de professores.

A respeito das políticas educativas, é fácil verificar que estão, hoje, baseadas em uma lógica de exposição pública dos resultados, muito visível com o sucesso global do Programme for International Student Assessment (PISA), da Organização para a Cooperação e Desenvolvimento Econômico (OCDE). Todos esses discursos têm como ponto forte a importância dos professores e da sua valorização. Também no Brasil, quem quiser receber uma salva de palmas de uma audiência, declara o seu amor à escola básica e aos professores. Mas o que se verifica na realidade? Uma desvalorização dos professores, e do seu estatuto profissional, em quase todos os países do mundo, e muito notoriamente no Brasil.

A respeito da formação de professores, pode dizer-se que é um campo em expansão, pelo menos na academia e na pesquisa educacional. Nunca se escreveu tanto como hoje acerca da formação docente, nunca houve tantos congressos e revistas científicas, tantos doutorados e pesquisas. Mas o que se verifica na realidade? Por um lado, um retrocesso nas políticas, com alguns países, como os Estados Unidos da América ou a Austrália, entre tantos outros, a regressarem ao tempo anterior às Escolas Normais. Por outro lado, uma estagnação das instituições universitárias de formação de professores que parecem incapazes de se renovarem e de adotarem as práticas mais adequadas para a formação profissional dos professores.

Quando analisamos essas duas dimensões, facilmente concordaremos que a tese central apresentada na conferência na USP, no dia 20 de maio de 1999, se mantém válida.

Se você fosse montar hoje um curso de História da Educação, e tivesse apenas oito aulas para desenvolvê-lo, o que você trabalharia?

Pergunta difícil, desde logo porque eu já não acredito em aulas e, muito menos, em um planejamento didático: tema - objetivos - desenvolvimento - avaliação, e por aí adiante. Na Europa, o Processo de Bolonha tem contribuído, e muito, para essa padronização da pedagogia universitária.

Acredito que podemos construir um problema e trabalhar sobre ele com os alunos. 0 que me interessa compreender são as configurações do modelo escolar, do tipo de educação e de escola que se tornaram dominantes ao longo do século XX. Como é que esse processo se definiu historicamente? Que outras possibilidades poderiam ter havido no passado? E que outras alternativas se apresentam no presente e no futuro? 
Com base nesse problema, é possível construir um seminário de pesquisa em oito sessões. A lógica do seminário é a de um caminho que se percorre, sem que tudo esteja definido à partida. Se perdermos a criatividade, o improviso e a capacidade de pensarmos em conjunto com os alunos, o ensino superior deixa de ter interesse. É certo que dá mais trabalho, aos professores e aos alunos, é certo que obriga a pesquisar e a estudar muito mais, mas, se não for para isso, então para que serve a universidade?

Desdobremos o problema definido em oito perguntas que poderão constituir a base de sessões de reflexão e de estudo, do presente para o passado e do passado para o futuro.

1) Quais são as características contemporâneas da educação e da escola? É possível olhar para essas características recusando a familiaridade e cultivando o estranhamento? Por que fechar as crianças em um edifício isolado, durante várias horas por dia, sentados em uma sala de aula sempre com os mesmos colegas e os mesmos professores? Etc;

2) As sociedades sempre educaram os seus filhos, mas quando é que a intenção educativa se tornou explícita, intencional, fruto de práticas e discursos diferenciados?

3) Como é que a intenção educativa foi adquirindo as configurações do modelo escolar? Como é que se constituiu uma cultura escolar? E por quê?

4) Por que é que as anteriores formas de educação (familiares, sociais, informais) são substituídas pela forma escolar e pelos grandes sistemas de ensino? Que outras possibilidades foram imaginadas? Por que é que não vingaram?

5) Como é que os Estados impõem a escolaridade obrigatória a todas as crianças, por um período de tempo cada vez mais longo? Poderia ter sido de outro modo?

6) De que forma a pedagogia moderna elabora uma imagem do bom aluno, baseada em princípios de autonomia, de liberdade e de responsabilidade que definem igualmente o bom cidadão"?

7) Quando surgem as primeiras críticas ao modelo escolar? Por que razão este modelo tem resistido com tanta solidez a diferentes tentativas de mudança e de inovação?

8) E hoje? 0 modelo escolar chegou ao fim? Ou é apenas uma ilusão? Que outras alternativas podem haver para educar os nossos filhos?

Talvez seguisse pelo caminho dessas perguntas.

Você é um grande especialista na história da educação e na educação comparada. Mas desenvolveu também estudos sobre o tema das histórias de vida de professores. Você diria que esse é um assunto sobre o qual os cursos de pedagogia e de formação de professores deveriam se debruçar? Será preciso estudar a constituição biográfica das identidades docentes?

Todos nos recordamos da obra marcante de Simone de Beauvoir, O segundo sexo, e da sua frase mais célebre: "Não nascemos mulheres, tornamo-nos mulheres”. Em um contexto muito diferente, podemos trazer esta frase para o debate docente: "Não nascemos professores, tornamo-nos professores". Deste modo, criticamos, desde logo, as teses do jeito ou da vocação para ser professor. Ninguém nasce professor, já feito. Mas, ao mesmo tempo, acentuamos que é preciso um trabalho pessoal para construir a identidade docente. Tornamo-nos professores através de uma reflexão que é também de cariz biográfico. 
No ensino ou na medicina não é possível separar a pessoalidade e a profissionalidade, o que somos como pessoas e a forma como agimos profissionalmente. A entrada no ensino superior devia ser sempre precedida de uma análise caso a caso, de entrevistas pessoais, de uma reflexão a respeito dos estudos que queremos seguir. Algumas universidades mantêm essa tradição que foi sendo abandonada com a massificação do ensino superior. Mas, em particular no caso das licenciaturas, como aliás no caso da medicina e de outros cursos nos quais a dimensão humana é central, deveria haver uma análise das histórias de vida, das motivações, do perfil e da predisposição dos candidatos para a profissão docente. A constituição biográfica das identidades docentes tem de ser uma preocupação central da formação de professores.

Aprender a ser professor exige um trabalho metódico, sistemático, de conhecimento das coisas, dos outros e de nós próprios. Interessa-me muito a vivência cultural e científica dos futuros professores: se não somos leitores, como poderemos inspirar nas crianças o gosto pela leitura? E o mesmo se diga da arte, da ciência, do esporte... Interessa-me muito a dimensão ética da docência, o seu ethos profissional, aquilo que Lee Shulman designa por imperativo pedagógico: não podemos assistir, impávidos, ao fracasso ou à desistência dos nossos alunos. Interessa-me muito a preparação dos professores para agirem em ambientes de incerteza: não são máquinas nem robôs, são pessoas.

Mas reconheço que esses três interesses não têm merecido grande atenção nos programas de formação de professores. Por isso, talvez valha a pena adaptar à docência a missão que Mikhail Epstein, há tempos, atribuiu à universidade: "Educar humanos por humanos para o bem da humanidade". Nessa frase está a humanidade dos alunos e o compromisso ético e social da profissão, mas está também a humanidade dos professores. Essa humanidade não pode ser esquecida, nem na formação de professores, nem na vida docente.

Hoje há uma profusão de discursos sobre educação que vêm de fora do campo da educação; vêm, por exemplo, do universo da economia ou mesmo do território das neurociências. Como você vê essa tendência?

Recordemos o triângulo que liga a ciência, as políticas e as práticas ou, dito de outro modo, a pesquisa científica, a ação política e o trabalho pedagógico. Em cada um desses vértices, afirma-se um discurso, dotado da sua própria legitimidade. Historicamente, os desequilíbrios nesse triângulo revelam momentos em que a verdade científica ou os projetos reformadores ou as dinâmicas profissionais ganharam maior destaque.

A novidade dos últimos anos é a expansão do que podemos designar pelos novos especialistas da educação, portadores de uma visão mais técnica e pragmática. Nas duas primeiras décadas do século XXI, assiste-se a um crescimento sem precedentes desses especialistas, agindo no interior de organizações internacionais, de fundações, de agências diversas, de think tanks, de Organizações não governamentais de empresas de consultoria e de recursos humanos.

Estes novos especialistas atuam nos três vértices, mas em uma dimensão paralela, como se houvesse um triângulo-sombra. Ficam apenas três exemplos. 
No vértice da ciência, note-se a importância das chamadas ciências da aprendizagem (learning sciences), dinamizadas por pessoas com origens várias: biologia, ciência cognitiva, ciência da computação, psicologia, linguística aplicada etc. Um grupo muito prestigiado de pesquisadores brasileiros, por exemplo, criou uma Rede Ciência para Educação, que não se destina a uma reflexão educativa ou pedagógica, mas a transportar para o campo educativo as descobertas de outros campos. Robert Lent, sobre isso, diz que "não é ensino de Ciências, nem educação científica, nem divulgação científica para crianças. É algo mais: aplicar na Educação as novas descobertas da Ciência”.

No vértice das políticas, é quase desnecessário referir a forma como o programa PISA, da OCDE, se tem vindo a impor como a principal referência para as decisões em matéria de educação.

No vértice das práticas, refıra-se à substituição dos tradicionais programas universitários de formação docente por iniciativas de formação curta, através de seminários intensivos, seguidos de uma atuação prática supervisionada por um professor mais experiente. Essas iniciativas são dirigidas e dinamizadas por pessoas, que, vindas de outras áreas, passaram a dedicar-se à educação, muitas vezes no âmbito de empresas ou de fundações.

Esses novos especialistas cumprem um papel muito importante. 0 seu contributo é da maior relevância. Mas não podemos fechar a reflexão educativa e pedagógica apenas em novas doutrinas, fortemente marcadas pela engenharia social (o que interessa é aquilo que funciona para a economia) ou pela engenharia humana (o que interessa é transladar os conhecimentos da biologia ou das neurociências para a educação). É preciso compreender a importância do conhecimento que vem de fora, mas é preciso também reforçar e consolidar o pensamento educativo de dentro, na sua tripla dimensão científica, política e prática.

Em alguns dos seus trabalhos, você aponta para a colegialidade docente como um dos desafios dos professores na contemporaneidade. 0 que você quer dizer com isso?

0 modelo escolar define uma pedagogia que se foi normalizando a partir de meados do século XIX, isto é, a partir da criação das Escolas Normais. Há uma coreografia que estabelece claramente o papel, o lugar e a ação do professor.

A metamorfose da escola vai, inevitavelmente, mudar esta coreografia. Em vez de um espaço, um tempo e uma ação, teremos vários espaços, vários tempos e várias ações. Uma das principais mudanças, como se percebe em muitas experiências em curso, é a passagem de um professor individual, que trabalha sozinho com a sua turma de alunos, para um trabalho conjunto entre professores, no quadro de uma diversidade de formas de organização pedagógica.

Historicamente, os professores constituíram-se como um corpo profissional muito sólido e reivindicativo. Os professores foram os primeiros grupos a organizarem-se em associações e, mais tarde, em sindicatos. No entanto, essa coesão sindical não se traduziu no dia-a-dia da organização do trabalho docente, onde sempre predominou uma ação individual. Por quê? Não é difícil descortinar, na própria lógica do modelo escolar, um 
recolhimento no espaço da sala de aula, daí decorrendo um apelo primordial à relação pedagógica entre um professor e os seus alunos.

Mas esta coreografia está a mudar, rapidamente. Uma escola é um espaço onde todos os professores têm de pensar coletivamente o seu trabalho, colaborando na definição de um projeto educativo mais amplo do que o simples planejamento das suas aulas. Mas, para além dessa lógica organizacional, o próprio desenvolvimento do trabalho pedagógico exige a cooperação entre vários professores.

Quando vemos fotografias das escolas do século XX, observamos que, para além do recreio ou das chamadas atividades extracurriculares, tudo se passa em uma sala de aula entre um professor e os seus alunos. Quando virmos fotografias das escolas do século XXI, perceberemos vários professores trabalhando no mesmo espaço com vários grupos de alunos.

A colegialidade docente, isto é, a possibilidade de os professores atuarem como um colégio (um coletivo), tem assim uma referência organizacional (o projeto educativo da escola) e uma referência pedagógica (novos ambientes educativos), mas tem ainda uma terceira referência: o reforço de uma profissionalidade docente baseada em um conhecimento profissional próprio, o que implica espaços de reflexão e de trabalho entre os professores, aquilo que os anglo-saxões designam por communities of practice (cuja melhor definição, neste caso, será comunidades de trabalho ou comunidades profissionais).

É neste triplo sentido que a colegialidade docente constitui, de fato, um dos grandes desafios para a profissão de professor e para a sua renovação no contexto da metamorfose da escola.

\section{Como você vê a realidade da escola brasileira hoje e quais suas perspectivas para o futuro?}

A escola brasileira precisa, ao mesmo tempo, de acabar o século XX e de entrar no século XXI.

Acabar o século XX. No Brasil, a escola ainda não cumpriu grande parte das promessas feitas no século XX, a começar pela promessa de dar uma educação de qualidade a todas as crianças. É inaceitável que um país como o Brasil tenha ainda níveis tão frágeis no que diz respeito aos resultados da aprendizagem. Em um tempo de tão prodigiosas descobertas científicas e tecnológicas, não somos capazes de ensinar a todas as crianças as bases do conhecimento? Não há desculpa. É preciso um movimento coletivo, geracional, de indignação e de construção das condições sociais e políticas que permitam, enfim, cumprir as promessas do século passado.

Entrar no século XXI. Mas, ao mesmo tempo, os educadores têm de se abrir ao futuro, ao futuro que já está presente nos alunos, nas escolas, na sociedade. Hoje, não estamos perante mudanças semelhantes às que tiveram lugar no tempo dos nossos pais ou dos nossos avós. A revolução digital coloca-nos perante novas maneiras de pensar, de conhecer, de comunicar e, sobretudo, de aprender. Podemos gostar mais ou menos, ter reservas, dúvidas, como eu tenho, mas há um antes e um depois. As escolas e os professores vivem um tempo de transição, de metamorfose. 
Se esquecermos o século XX e quisermos dedicar-nos apenas ao século XXI, estaremos a alimentar uma ilusão futurista que ignora a realidade. Se esquecermos o século XXI e quisermos dedicar-nos apenas ao século XX, estaremos a perder as possibilidades do futuro.

Como você avalia, de maneira mais ampla, a atualidade do modelo escolar, em termos internacionais? É possível e é válida, ainda, a defesa da escola pública de Estado como uma plataforma de política democrática?

A escola é uma instituição insubstituível, assim como os professores, mas o modelo escolar, tal como o defini anteriormente, já não responde às necessidades do futuro. Não é a tecnologia que nos vai salvar, mas a compreensão crítica de que precisamos de novos ambientes educativos.

Nos últimos anos, muita gente acreditou que o digital ia ser uma janela fantástica, que nos daria entrada em todos os mundos, culturas e conhecimentos. A ilusão está a tornar-se pesadelo. Uma das nossas maiores surpresas, hoje, é a fragmentação e o hiperindividualismo que reinam no cibermundo. Contrariamente ao que esperávamos, a rede não tem sido uma porta de acesso à diversidade, mas antes um lugar onde vamos à procura dos que pensam como nós, dos que partilham das nossas mesmas crenças e convicções. Falta-nos um lugar de encontro, onde se possa construir um diálogo informado, com bases culturais e científicas. Esse lugar não é o cibermundo. Esse lugar é a escola, e é por isso que precisamos dela, mais do que nunca, uma escola que seja capaz de reconstruir o comum, tudo o que nos junta em uma mesma humanidade e em um mesmo planeta.

Não se trata de defender uma comunidade de identidade, mas uma comunidade de diálogo e de ação, que valorize aquilo que fazemos uns com os outros, independentemente de quem somos ou de onde viemos. Em um tempo de fragmentação, de divisão e individualismo, a escola tem de reconstruir as condições para uma vida em comum. Não se trata de unir, artificialmente, o que é diferente, mas de criar os ambientes que permitam pensar em conjunto, uns com os outros, partilhar uma reflexão sobre os mesmos objetos, isto é, sobre os nossos problemas comuns. Não é unificação a partir de um qualquer imaginário do mundo, mas antes abertura a práticas de colaboração e de cooperação.

É nesse sentido que venho defendendo a ideia do espaço público de educação, que é mais amplo do que o espaço escolar propriamente dito. Tentarei explicar.

No século XIX, a educação foi trazida para dentro de um lugar sagrado, a escola. Hoje, precisamos de um movimento de profanação, no sentido que lhe dá Giorgio Agamben, isto é, devolver um objeto sagrado ao uso público. Dito de outro modo: precisamos trabalhar em conjunto para a constituição de um espaço público que junte a escola com outras instituições, professores com pais e com outros atores sociais. Não se educa apenas no interior do recinto escolar.

0 espaço público da educação tem de ser uma esfera de discussão, mas também de deliberação e de ação. Não se trata apenas de ouvir os cidadãos, mas de os inscrever como parceiros em um esforço educativo que pertence ao conjunto da cidade, da polis. Só assim conseguiremos criar novos vínculos e responsabilidades, e evoluir para uma maior 
presença dos professores e da sociedade na construção das políticas públicas de educação. Alguns preferem chamar-lhe cidade educadora, e a metáfora faz sentido; eu prefiro chamar-lhe espaço público de educação, afırmando a sua importância como plataforma de política democrática, para usar os termos da pergunta.

\section{Quais são os principais desafios dos cursos de formação de professores?}

A construção de uma política integrada e coerente de formação de professores assenta-se em quatro bases principais:

a) A formação de professores é uma formação profissional universitária. A formação de professores deve ser pensada como uma formação profissional de nível superior, isto é, uma formação para uma profissão. Nesse sentido, a analogia óbvia é com outras formações profissionais universitárias, como os médicos ou os engenheiros;

b) A formação de professores necessita de um lugar institucional de referência. Como para as restantes formações profissionais, também a formação de professores necessita de um lugar institucional, dentro da Universidade. Em um quadro de fragmentação das licenciaturas, como aquele que atualmente existe, é difícil, ou mesmo impossível, construir um percurso coerente de formação. Nesse sentido, sublinha-se a importância desta institucionalidade, aquilo que venho designando por um terceiro lugar. No ano passado, a convite do Reitor da Universidade Federal do Rio de Janeiro, desenvolvi várias atividades no sentido da construção de um Complexo de Formação de Professores. É um belo projeto, em curso, dos colegas do Rio de Janeiro;

c) O lugar da formação de professores é entre a Universidade e a cidade. A formação de professores necessita de um lugar interno de coordenação, decisão e concretização. Mas esse lugar tem uma dimensão interna e uma dimensão externa, de ligação com as escolas das redes. Hoje, para formar um médico, precisamos de hospitais modernos, de referência, com boas condições, humanas e tecnológicas. 0 que é verdade para os médicos é verdade também para os professores. Para formar um professor, é fundamental haver uma presença e uma vivência em escolas de referência. A chave para a mudança da formação de professores está na criação de um ambiente escolar estimulante e inovador, o que só será possivel através de uma ligação forte entre a Universidade e as redes escolares; e

d) A formação de professores deve ser pensada no ciclo do desenvolvimento profissional: formação inicial, indução profissional, formação continuada. A responsabilidade primeira da Universidade é com as licenciaturas (formação inicial dos professores). Porém, não é possível conceber a formação para uma profissão sem, ao mesmo tempo, pensar o período de integração profissional, nomeadamente através de programas de residência docente, e o período de exercício profissional com programas de formação continuada.

Em um de seus livros, você diz que, em educação, tudo o que é evidente, mente. 0 que você quer exatamente dizer com isso? 
Em Portugal e no Brasil há dois temas sobre os quais toda a gente sabe, sobre os quais toda a gente tem uma opinião definitiva: o futebol e a educação. Deixo de parte o futebol. E a educação? Todos fomos ou somos alunos, pais, avós, todos conhecemos a escola, todos temos certezas sobre o que deve e não deve ser feito.

Todos os dias ouvimos expressões como: "Hoje, os alunos não respeitam nada, nem ninguém"; "Já não há valores como antigamente"; "No meu tempo, aprendia-se a sério na escola, hoje saem de lá sem saber nada"; "Os alunos deviam ser obrigados a esforçar-se, mas na escola é tudo uma brincadeira”; "Os professores já não têm nenhuma autoridade sobre os alunos"; e por aí adiante.

Estas opiniões são apresentadas como evidências, mas são falsas evidências. Quando se estudam esses assuntos, percebemos que a realidade é bem mais complexa. Por isso, escrevi: Cuidado, é preciso desconfiar dessas evidências, em educação tudo o que é evidente mente. Não podemos ficar pela superfície das coisas, temos de ir mais longe e mais fundo na nossa compreensão da educação. Caso contrário, tornar-nos-emos repetidores de banalidades.

Você publicou recentemente uma adorável Carta a um jovem investigador em educação, na Revista Investigar em Educação. Qual mensagem você deixa para os jovens investigadores da educação? E para os jovens professores?

Estranha associação ou talvez não. A pergunta trouxe-me ao espírito uma passagem de Em busca do tempo perdido, de Marcel Proust: $O$ que é importante na vida não é o que se ama, é amar. Investigadores e professores, não interessa tanto os temas que pesquisam ou as matérias que ensinam, mas a capacidade de se investirem no seu trabalho, de lhe darem um sentido pessoal e social.

Não há nada pior do que a falta de sentido. Os jovens pesquisadores e os jovens professores não podem lançar-se em uma vida rotineira, repetitiva, aborrecida. No meio de muitas dificuldades, na ciência e no ensino, que não podemos ignorar, temos de lhes pedir para se deixarem surpreender, para adotarem novas maneiras de ver e de pensar, para inscreverem a própria palavra.

Os jovens precisam de se preparar, ainda que seja difícil, ou mesmo impossível, antecipar os próximos 30 ou 40 anos da ciência e da educação. Em 1854, em um discurso que leio e releio muitas vezes, Louis Pasteur conta uma história passada com Benjamin Franklin: "Quando assistia à primeira demonstração de uma descoberta puramente científica, perguntavam à sua volta: Mas para que é que isto serve? E Franklin respondeu: E para que serve a criança que acabou de nascer?" E, no entanto, conclui Pasteur, nesse dia do nascimento cada de um já possui os germes desconhecidos dos talentos que o distinguem. 0 discurso continua com a descoberta, por acaso, do telégrafo eléctrico: "Por acaso, talvez, mas nunca se esqueçam que nos campos da observação o acaso favorece sempre as mentes preparadas".

Preparem-se, pois, diligentemente, para estarem à altura dos desafios contemporâneos da ciência e da educação. Uma herança não se respeita pela repetição, mas sim pela recriação, pela reinvenção. 
Você foi reitor da Universidade de Lisboa por muitos anos - e desenvolveu um notável trabalho de fortalecimento daquela instituição. Como você vê a realidade universitária hoje - em termos internacionais? Quais são os desafios que possuem hoje especialmente as universidades portuguesas e brasileiras?

As universidades vivem um tempo-forte, de grandes expectativas. Ano após ano aumenta o número de estudantes. A ciência e a tecnologia adquirem um papel cada vez mais central nas sociedades contemporâneas. Ninguém consegue imaginar, hoje, uma grande cidade sem uma grande universidade.

Mas este tempo é também de dificuldades e de hesitações. De modo simplista, gostaria de chamar a atenção para os prejuízos de duas tendências que vou designar, imperfeitamente, por corporativismo e empresarialismo.

Por corporativismo quero referir-me às formas de fechamento interno e de resistência à mudança, a processos de proteção do que está instituído (poderes professorais, departamentais etc.). Essa tendência asfixia as universidades, coloca-as em estado de letargia e impede a sua renovação.

0 empresarialismo, muito em voga nos nossos dias, procura trazer o exemplo das empresas e da sua gestão para dentro das universidades, através de discursos de modernização, de governança e de excelência que têm desequilibrado as instituições no sentido das áreas tecnológicas, da empregabilidade e do empreendedorismo.

0 que nos faz falta é um entendimento claro da missão da Universidade, da sua diversidade, da sua liberdade e dos seus desafios. Precisamos de novos ambientes pedagógicos, pois, nos atuais anfiteatros e salas de aula, não é possível criar dinâmicas estimulantes de aprendizagem. Precisamos de uma ciência da convergência, focada nos grandes temas do mundo (a água, a energia, os transportes, a saúde, o envelhecimento, as desigualdades etc.), pois a organização disciplinar de centros e grupos de pesquisa é muito limitada e não permite avançar em um conhecimento complexo. Precisamos de uma universidade aberta, que seja uma plataforma baseada na cidade, como propõe Christine Ortiz; aquilo que em Lisboa e em outros locais se foi chamando a univercidade.

A vida das sociedades do século XXI passa, em grande parte, pelas universidades. Se olharmos para fora de nós, encontraremos os motivos que nos chamam à responsabilidade e nos apontam os caminhos da mudança. Foi o que fizemos na Universidade de Lisboa, uma Universidade que quer ser de Lisboa para o mundo.

Qual questão você gostaria de ter respondido e que eu não fiz?

Já afırmou, em várias ocasiões, que o Brasil é muito importante na sua vida. Por quê?

\section{Publicações de António Nóvoa}

NÓVOA, António. A imprensa de educação e ensino: repertório analítico (séculos XIX-XX). Lisboa: Instituto de Inovação Educacional, 1993. 
NÓVOA, António. Biografia. Lisboa, jul. 2016. (Mimeo).

NÓVOA, António. Carta a um jovem investigador em educação. Investigar em Educação, Porto, n. 3, p. 13-21, 2015.

NÓVOA, António. Curriculum vitae. Lisboa: Jul. 2016. (Mimeo).

NÓVOA, António. Educação 2021: para uma história do futuro. In: CATANI, Denice Barbara; GATTI JÚNIOR, Décio (Org.). 0 que a escola faz? Elementos para a compreensão da vida escolar. Uberlândia: Edufu, 2015. p. 51-69.

NÓVOA, António. Evidentementemente: histórias da educação. Porto: Asa, 2005.

NÓVOA, António. Histoire \& comparaison. Lisboa: Educa, 1998.

NÓVOA, António. História da educação. 1994. (Tese de Agregação) - Faculdade de Psicologia e Ciências da Educação da Universidade de Lisboa, Lisboa, 1994.

NÓVOA, António. La construction du modèle scolaire dans l'Europe du Sud-ouest (Espagne, France, Portugal): des années 1860 aux années 1920. 2006. Tese de doutorado - Universidade de Paris IV, Sorbonne, Paris, 2006.

NÓVOA, António. Le temps des professeurs: analyse socio-historique de la profession enseignante au Portugal (XVIII' ${ }^{2}$-XXa siècle). v. 1-2. Lisboa: Instituto Nacional de Investigação Científica, 1987.

NÓVOA, António. Lumières sur l'école: comment interpréter les debats éducatifs contemporains dans le monde? Administration et Éducation, n. 3, p. 9-17, 2012.

NÓVOA, António. 0 regresso dos professores. In: CONFERENCE ON TEACHER PROFESSIONAL DEVELOPMENT FOR THE QUALITY AND EQUITY OF LIFELONG LEARNING, 2007, Lisbon". Conference... Lisboa: European Commission, 2007. Comunicação apresentada.

NÓVOA, António. Os professores e as reformas de ensino na viragem do século (1886-1906). Porto: Asa, 1993.

NÓVOA, António. Os professores na virada do milênio: do excesso dos discursos à pobreza das práticas. Educação e Pesquisa, São Paulo, v. 25, n. 01, p. 11-20, jan./jun. 1999.

NÓVOA, António. Pensar la escuela más allá de la escuela. Con-Ciencia Social, Sevilla, v. 17, p. 27-38, 2013.

NÓVOA, António. Professores: imagens do futuro presente. Lisboa: Educa, 2009.

NÓVOA, António (Org.). Profissão professor. Porto: Porto Editora, 1991.

NÓVOA, António. Teachers: how long until the future? In: FLORES, Maria Assunção et al. Back to the future: legacies, continuities and changes in educational policy, practice and research. Rotterdam: Sense, 2013. p. 29-37.

NÓVOA, António. The right education in Europe: when the obvious is not so obvious. Theory and Research in Education, New York, v. 5, n. 2, p.143-151, 2007.

NÓVOA, António. The teaching profession in Europe: historical and sociological analysis. In: SWING, Elizabeth S.; SCHRIEWER, Jurgen; ORIVEL, François. Problems and prospects in European education. Westport: Praeger, 2000. p. 5-71. 
Carlota BOTO

NÓVOA, António. Vidas de professores. Lisboa: Porto Editora, 1992.

NÓVOA, António; Ó, Jorge Manuel Ramos do (Org). Fundação Calouste Gulbenkian. Serviço de Educação. A escola na literatura: 40 textos de autores portugueses. Lisboa: FCG, 1997.

NÓVOA, António; SCHRIEWER, Jürgen (Org.). A difusão mundial da escola: alunos, professores, currículo, pedagogia. Lisboa: Educa, 2000. 